\title{
Is single layer graphene a promising anode for sodium-ion
}

\section{batteries?}

\author{
Alberto Ramos, ${ }^{\star}$ Ignacio Cameán, Nuria Cuesta and Ana B. García \\ Instituto Nacional del Carbón, CSIC, 33011 Oviedo, Spain
}

In an attempt to find an adequate carbon material to achieve a successful reversible adsorption of $\mathrm{Na}^{+}$ions, single layer graphene, is experimentally investigated in this work, for the first time, as anode for sodium-ion batteries. To this end, single layer graphene that was grown on copper foil by chemical vapor deposition was subjected to extended galvanostatic cycling and to cyclic voltammetry in the potential range of $0-2.8 \mathrm{~V}$ versus $\mathrm{Na} / \mathrm{Na}^{+}$. Regardless of the current density and electrolyte formulation used, the amount of $\mathrm{Na}^{+}$ions adsorbed/desorbed reversibly per surface area (specific reversible cell capacity) was very modest and comparable to that obtained with bare copper electrodes of reference, thus suggesting that the reversible capacity of the single layer graphene electrode is mostly due to the electrochemical response of the copper substrate. These experimental results clearly agree with recent theoretical calculations showing that the adsorption of $\mathrm{Na}^{+}$ions on the surface of single layer graphene is energetically unfavourable unless that surface includes significant defects density.

Keywords: single layer graphene; anode; sodium-ion battery

\footnotetext{
Corresponding autor. Tel.: 34-985119090
}

E-mail addresses: alberto.ramos@incar.csic.es, icamean@incar.csic.es, n.cuesta@incar.csic.es, anabgs@incar.csic.es 


\section{Introduction}

Sodium-ion batteries (SIBs) are currently considered an attractive alternative to lithium-ion batteries (LIBs) particularly for application in stationary large-scale electric energy storage systems (EES) owing to the abundant resources, low cost and safety of sodium as compared with lithium [1,2]. In these systems, the cost is the overriding issue as they are made up of a great number of batteries, whereas the energy density at the battery unit level is not a critical factor, thus being a realistic option for the application of the SIBs since they usually have lower energy density than their counterparts LIBs. However, as it has been stressed in a recent publication [3], the cost reduction that could be achieved by using SIBs may not be significant in terms of the final energy cost $(\$ / W h)$. Therefore, the energy density of the SIBs should be improved to allow their development and subsequent implementation as EES. To this end, a variety of electrode materials [1-4], cathode and anode, and electrolytes [1,2,5,6] for SIBs have been investigated, mainly, in the last two years. The results of the research in the field of cathode materials, several of them obtained by the simple replacement of lithium by sodium in the analogue compound, appear promising with a number of layered transition metal oxides, phosphates and fluorophosphates showing acceptable reversible capacity, stability and relatively high operating potentials $[1,4]$.

In contrast, up to now the progress in the development of anode materials with high specific capacities and low working potential to improve the energy density of the sodium-ion battery is very limited, mainly because of the inability of 
the graphite and/or graphitic carbons - the anodic choice par excellence in LIBs to reversibly intercalate sodium ions between the carbon layers to any appreciable extent. As an example, compounds with a formulation of $\mathrm{NaC}_{186}$ were calculated after electrochemical intercalation of $\mathrm{Na}^{+}$in graphite [7] against the typical $\mathrm{LiC}_{6}$ graphite intercalation compound that is formed in LIBs. Based on theoretical calculations, this difference has been assigned to the extremely weak attractive interactions forces between the graphite layers and the intercalated $\mathrm{Na}^{+}$ions [8]; as a result, sodium is deposited as metal on the electrode surface rather than intercalated. Moreover, the sodium graphite intercalation compounds $\left(\mathrm{NaC}_{\mathrm{x}}\right.$ with $\mathrm{x}$ $=36,16,12,8,6)$ are unstable [9]. In fact, they do not exist under moderate conditions, which was reported to be a consequence of the clash between the graphite structure (graphite is stressed when some $\mathrm{Na}^{+}$ions intercalate into it) and the size of the $\mathrm{Na}^{+}$ion (its ionic radius is approximately $0.3 \AA$ larger than that of $\mathrm{Li}^{+}$ ion, this difference leading to changes in thermodynamic and kinetic properties) $[9,10]$. Therefore, efforts have been focused on the identification of other host carbon materials to achieve a successful reversible intercalation/insertion of the larger $\mathrm{Na}^{+}$anions. Thus, a variety of carbons having a certain degree of porosity, a low-ordered structure consisting of few-layers graphite nanocrystallites (graphite domains) and different morphologies, including hard and soft carbons [5,7,11-15], carbon fibers and nanofibers [16-20], spherical carbons [21], hollow carbon nanowires [22] and nanospheres [23], reduced graphene oxide, [24] pyrolytic carbons from graphite oxide [25], as well as highly disordered carbon composites $[26,27]$ have been investigated as anodes for SIBs. Good results as regards capacity and cycling stability were achieved with some of these carbons, the rate 
capability and particularly, the low coulombic efficiency during the first charge/discharge cycle due to the relatively large surface area (as compared with graphitic carbons) being the main drawbacks to overcome. In these porous disordered carbons, the electrochemical storage of $\mathrm{Na}^{+}$ions occurs through two predominant mechanisms, insertion between the graphene layers of the small graphitic clusters in the higher potential region $\left(\sim 1.5-0.1 \mathrm{~V} v s \mathrm{Na} / \mathrm{Na}^{+}\right)$resulting in a sloping voltage profile, and/or adsorption by filling the porous structure as showed by the plateau at the lowest potentials $\left(<0.1 \mathrm{~V}\right.$ vs $\left.\mathrm{Na} / \mathrm{Na}^{+}\right)[7,11,19,23]$. Thus, no voltage plateaux were observed in the electrochemical profiles of electrospun carbon nanofibers [19] and reduced graphene oxide [24], indicating that the capacity was mainly due to the sodium insertion into the graphene layers. A common feature for these carbons is the large interlayer spacing [19,23,24], all of them having values $\geq 0.37 \mathrm{~nm}$, which has been determined from theoretical calculations to be the critical minimum value required to allow good reversible $\mathrm{Na}^{+}$ ion insertion [22]. On the contrary, a large proportion of the capacity provided by other carbons was ascribed to the adsorption of sodium into the pores [7]. In any event, the former mechanism should be preferred since the $\mathrm{Na}^{+}$ion pore-filling potential is close to that of the metal itself which may cause sodium plating. Moreover, a large fraction of the sodium storage between the graphene layers was generally accompanied by a superior anodic rate performance of the material [19, 22-24]. In conclusion from these studies, it seems that graphite-like materials with large interlayer distance and low porosity are potentially the most suitable anodes to allow the development of the SIBs. In this context, expanded graphite with a large interlayer distance $(0.43 \mathrm{~nm})$ and a low surface area $\left(\sim 30 \mathrm{~m}^{2} \mathrm{~g}^{-1}\right)$ have been 
successfully used for the first time as anode material for SIBs [28]. Therefore, the diffusion of the $\mathrm{Na}^{+}$ions in carbon materials during the electrochemical process will not be a problem if an adequate structure is designed or selected.

In an attempt to find the above mentioned ideal carbon structure, graphene monolayer or single layer graphene (SLG), a novel 2D material with very high electronic mobility is experimentally investigated in this work, for the first time, as anode for sodium-ion batteries. To this end, single layer graphene that was grown on copper foil by chemical vapor deposition (CVD) was subjected to galvanostatic cycling versus $\mathrm{Na} / \mathrm{Na}^{+}$using constant current intensity. CVD-grown SLG on copper foil has been already applied as anode for the LIBs counterparts [29,30]. Despite this, the exact mechanism of $\mathrm{Li}^{+}$ions storage in the SLG is still a subject of controversy. It has been recently suggested and even experimentally demonstrated that they are surface adsorbed in both sides of the Cu-deposited SLG [29,31]. Because of the high surface area $\left(2675 \mathrm{~m}^{2} \mathrm{~g}^{-1}\right.$ counting the two sides) and the very low mass/surface ratio of this material, huge specific capacities were measured in LIBs (i. e. $13263 \mathrm{~mA} \mathrm{~h} \mathrm{~g}^{-1}$ in ref. 27). However, the capacity values expressed in terms of surface unit were modest $\left(<0.05 \mathrm{~mA} \mathrm{~h} \mathrm{~cm}^{-2}\right)[29,30]$ and lower than that of graphite anode [32]. On the basis of these results, it is evident that for the implementation of SLG as anode in LIBS, novel battery architectures of reduced dimensions and lighter should be designed in parallel. However, recent studies have concluded as regards the electrochemical adsorption of $\mathrm{Li}^{+}$ions on the surface of SLG that (i) it does not occur unless that surface showed defects [33] and the amount is smaller than that previously 
predicted [32]. With these precedents in mind, in this work, emphasis was placed on the nature of the interaction of the $\mathrm{Na}^{+}$ions with the SLG.

\section{Experimental section}

Two-electrode (working + counter) Swagelok-type laboratory cells were used for the electrochemical characterization. The working electrodes were single layer graphene CVD-grown on copper discs of $12 \mathrm{~mm}$ of diameter and $18 \mu \mathrm{m}$ of thickness of commercial origin (SLG/Cu electrode), with a surface coverage $>95 \%$ and a grain size up to $10 \mu \mathrm{m}$ (see Figure S1 in ESI for a Raman spectrum and SEM and TEM images of the SLG provided by the supplier). For comparative purposes, bare copper discs of the same diameter (Cu electrode) of high purity (> 99.99\%) were also used as working electrodes. In all cases, metallic sodium disc of $12 \mathrm{~mm}$ of diameter and $\sim 1 \mathrm{~mm}$ of thickness were the counter electrodes. The electrodes in the cell were separated by two micro-fiber glass discs impregnated with one of the following electrolyte solutions: $1 \mathrm{M} \mathrm{NaPF}_{6}$ in 1:1 (w:w) ethylene carbonate (EC): diethyl carbonate (DEC), $1 \mathrm{M} \mathrm{NaPF}_{6}$ in 1:1 (w:w) EC:propylene carbonate (PC), or $1 \mathrm{M} \mathrm{NaClO}_{4}$ in $\mathrm{PC}$. The cell assembly was carried out in a dry box under argon atmosphere with oxygen and water contents below $0.1 \mathrm{ppm}$.

The electrochemical measurements of the cells (galvanostatic cycling and cyclic voltammetry) were conducted in a Biologic multichannel VMP2/Z potentiostat. The galvanostatic cycling was carried out in the $2.8-0.003 \mathrm{~V}$ potential range versus $\mathrm{Na} / \mathrm{Na}^{+}$using constant current intensity, during 50 cycles at $5 \mu \mathrm{A} \mathrm{cm}$ 
${ }^{2}$ and up to 500 cycles at $50 \mu \mathrm{A} \mathrm{cm}^{-2}$. The cyclic voltammograms were collected at a scan rate of $0.1 \mathrm{mV} \mathrm{s}^{-1}$ for 5 cycles in the $0-2.8 \mathrm{~V}$ potential range versus $\mathrm{Na} / \mathrm{Na}^{+}$.

\section{Results and discussion}

\subsection{Interaction of $\mathrm{Na}^{+}$ions with the single layer graphene}

The mechanism of interaction of the $\mathrm{Na}^{+}$ions with the SLG was studied through cyclic voltammetry in the potential range of $0-2.8 \mathrm{~V} v s \mathrm{Na} / \mathrm{Na}^{+}$. The cyclic voltammograms (CVs) of the cycles 1,2 y 5 of SLG/Cu electrode are reported in Fig. 1. For comparison, the CVs of the bare $\mathrm{Cu}$ electrodes were also included in this figure. All these experiments were performed using $1 \mathrm{M} \mathrm{NaPF}_{6}$ (EC:DEC, 1:1, w:w) as the electrolyte solution. In general terms, the intense cathodic and anodic peaks due to the insertion and de-insertion processes of $\mathrm{Na}^{+}$ions in carbon materials $[5,7,11-28]$ do not appear in the CVs of SLG/Cu electrodes. More specifically, the CV of cycle 1 displays a significant cathodic current that has been previously observed in the study of the interaction of $\mathrm{Li}^{+}$ions with SLG [34] and attributed to the formation of a solid electrolyte interphase (SEI) layer as a consequence of the electrolyte irreversible reduction. As expected from its origin, the cathodic current decreases noticeably after the first cycle; however, it still rules over the electrochemical response of the SLG/Cu electrode $v s \mathrm{Na} / \mathrm{Na}^{+}$along cycling (Fig.1). Thus, the CVs of the cycle 2 and particularly, of cycle 5 show some weak and low defined cathodic peaks at potentials below $1 \mathrm{~V} v s \mathrm{Na} / \mathrm{Na}^{+}$that can be associated with the adsorption of $\mathrm{Na}^{+}$ions. 
A comparative inspection of the $\mathrm{CVs}$ of $\mathrm{SGL} / \mathrm{Cu}$ and bare $\mathrm{Cu}$ electrodes in Fig. 1 shows only small differences between them, which can basically be summarized in the presence of a cathodic peak around $2 \mathrm{~V} v s \mathrm{Na} / \mathrm{Na}^{+}$in the first cycle curve of the later electrode. Considering that the degradation process of $\mathrm{LiPF}_{6}$ electrolyte occurs at this potential in bare $\mathrm{Cu}$ electrode vs $\mathrm{Li}^{-} \mathrm{Li}^{+}$[35], this peak can be associated with the degradation of the sodium salt $\left(\mathrm{NaPF}_{6}\right)$ of the electrolyte during the first cycle. This peak disappears in the following cycles, and thus, after five cycles the CVs are similar as regards both the peaks and the integrated area under the curve (Fig.1). Thus, the above mentioned weak cathodic peaks (below $1 \mathrm{~V}$ ) also appear in the $\mathrm{CV}$ of the bare $\mathrm{Cu}$ electrode, from which the electrochemical adsorption of the $\mathrm{Na}^{+}$ions on the surface of the copper can be at first inferred. Similar cathodic peaks were previously observed in the CV of bare $\mathrm{Cu}$ electrode versus $\mathrm{Li} / \mathrm{Li}^{+}$[29]; however, in the aforementioned work, the integrated area under the CV curve was smaller than that of the corresponding SLG/Cu electrode.

The profiles of the potential vs capacity plots in Fig. 2 clearly demonstrated that the $\mathrm{Na}^{+}$adsorption process on the surface of both SLG/Cu and bare $\mathrm{Cu}$ electrodes is reversible. Thus, in addition to the discharge curve of basically constant slope below 1.5-1.0 V which corresponds to the small and low defined cathodic peaks appearing in the voltammograms (Fig.1), all of them showed a similar charge curve due to desorption of the $\mathrm{Na}^{+}$ions from the electrode surface (charge curves correspond to the uptake of $\mathrm{Na}^{+}$ions since these are half-cells). However, the latter process occurs at higher potentials (below $1.8 \mathrm{~V}$ ). Comparable discharge-charge profiles were previously obtained during the 
galvanostatic cycling of SLG/Cu electrodes vs $\mathrm{Li} / \mathrm{Li}^{+}[29]$. As regards the bare $\mathrm{Cu}$ electrode of reference, it also shows adsorption-desorption of $\mathrm{Na}^{+}$ions on the surface during the galvanostatic cycling $v s \mathrm{Na} / \mathrm{Na}^{+}$with remarkable difference between discharge (below 1.0 V) and charge (above 1.5 V) potentials (Fig. 2).

\subsection{Electrochemical performance of SGL/Cu electrode}

In the first place, SGL/Cu electrodes were subjected to galvanostatic cycling at $50 \mu \mathrm{A} \mathrm{cm}^{-2}$ current density for 500 discharge-charge cycles in the presence of $1 \mathrm{M} \mathrm{NaPF}_{6}\left(\mathrm{EC}: \mathrm{DEC}\right.$ or EC:PC, 1:1, w:w) and for 100 cycles using $1 \mathrm{M} \mathrm{NaClO}_{4}$ (PC) electrolyte solutions. The plots of reversible capacity and cycling efficiency vs cycle number (from the second cycle) are provided in Fig. 3. Specific surface capacities of $\sim 1 \mu \mathrm{A} \mathrm{h} \mathrm{cm}{ }^{-2}$ were measured at the end of cycling in all cases. When normalized to their masses (the mass/surface ratio of the $\mathrm{Cu}$ deposited SLG is about $\left.7.4 \times 10^{-4} \mathrm{~g} \mathrm{~m}^{-2}\right)$, the capacities $\left(\sim 13500 \mathrm{~mA} \mathrm{~h} \mathrm{~g}^{-1}\right)$ are three orders of magnitude over those measured for other carbon materials which currently are investigated as anode in SIBS [1-6,10-28] and furthermore, similar to the values reported for the use of SLG/Cu electrodes in lithium-ion batteries [29]. However, a priori, it appears a very poor electrochemical response from the point of view of the use of SLG/Cu anodes in SIBs as enormous electrode dimensions will be required to achieve these high capacities. As can be observed in Fig. 3, the cells start to show good electrochemical performance in terms of cycling stability as well as coulombic efficiency ( $\geq 90 \%, \geq 85 \%$ for $\mathrm{NaClO}_{4}$ in PC electrolyte) after 20 
discharge-charge cycles. However, during the initial cycles (2-20), these electrochemical parameters, particularly the capacity retention, were much lower. For example, $72 \%$ of the total discharge capacity loss occurs in this period for the SLG/Cu in $1 \mathrm{M} \mathrm{NaPF}_{6}$ (EC:DEC) electrolyte solution. This capacity fading may be explained on the basis of the evolution of the charging and discharging cell overpotential during cycling since it was found to increase continuously from cycle 1 to cycle 20 (see plot of the normalized voltage vs capacity profile in Fig. S2 of the Electronic Supporting Information) which may be associated with the increase of the charge transfer resistance of the SEI layer [5]. Therefore, the formation of continuously growing SEI and electrolyte decomposition/consumption may be predicted. In addition, over-large irreversible capacity values (> 90\%) were measured in the first discharge-charge cycle of the cells in the presence of the three electrolyte solutions.

The discharge capacities of the cells in the first, second, twentieth and last cycles $(50,100$ or 500$)$ at 5 and $50 \mu \mathrm{A} \mathrm{cm}{ }^{-2}$ current densities as well as the irreversible capacity in the first cycle and the capacity retention along cycling for SLG/Cu electrodes are compiled in Table 1. For comparison, data of bare $\mathrm{Cu}$ electrode of reference with $1 \mathrm{M} \mathrm{NaPF}_{6}$ (EC:DEC) electrolyte solution are also included. Overall, as regards SLG/Cu electrodes, an improvement of the discharge capacity and the capacity retention upon cycling of the cells was observed by lowering the current density. In parallel, a remarkable decrease of the overpotential occurs (see Fig. S2 in ESI). Thus, SLG/Cu electrodes with $\mathrm{NaPF}_{6}$ (EC:DEC) and $\mathrm{NaClO}_{4}$ (PC) electrolytes exhibit discharge capacity values at the end of cycling of $\sim 14 \mu \mathrm{A} \mathrm{h} \mathrm{cm} \mathrm{cm}^{-2}$ and capacity retentions of $\sim 68 \%$ at a current 
density of $5 \mu \mathrm{A} \mathrm{cm}{ }^{-2}$. However, the cycling efficiency was found to decrease remarkably at this very low current density for the three electrolytes studied, probably as consequence of sodium plating and higher electrolyte decomposition due to the longer exposure at low potentials vs $\mathrm{Na} / \mathrm{Na}^{+}$(see Fig. S3 in ESI and Fig. 3). The performance during the extended (500 cycles) cycling at $50 \mu \mathrm{A} \mathrm{cm}^{-2}$ of the bare $\mathrm{Cu}$ electrode of reference is comparable to that of SLG/Cu electrode (Table 1). Thus, a significant capacity fading occurs, mainly along 2-20 cycles, resulting in very low capacity retention and specific capacities close to $1 \mu \mathrm{A} \mathrm{h} \mathrm{cm}{ }^{-2}$ at the end of cycling. Furthermore, similar evolution of the cycling efficiency reaching values $>90 \%$ after the initial cycles was also determined (see Fig. S4 in ESI and Fig. 3). The unique remarkable difference between them was observed when the current density was decreased to $5 \mu \mathrm{A} \mathrm{cm}{ }^{-2}$ since the cell capacity with the bare $\mathrm{Cu}$ electrode basically does not change (Table 1). However, this difference cannot be considered very much significant because of the low coulombic efficiency of the cell with both SLG/Cu and bare $\mathrm{Cu}$ anodes at this very low current density (see Fig. S3 and S4 in ESI). In summary, it can be inferred that, under the experimental conditions studied in this work, the amount of $\mathrm{Na}^{+}$ ions adsorbed on the surface of the single layer graphene is very small and basically correspond to the electrochemical response of the $\mathrm{Cu}$ substrate. These experimental results clearly prove recent theoretical calculations [36], which have showed that the adsorption of $\mathrm{Na}^{+}$ions on pristine SLG is energetically unfavourable (adsorption energies of $+0.50 \mathrm{eV}$ to $+0.71 \mathrm{eV}$, depending on the site were calculated). As mentioned in the introduction of this paper, positive energy adsorption values for $\mathrm{Li}$ on single layer graphene have also been 
calculated in previous studies [33]. In this context, the authors have concluded that the measured small cell capacities (e. g. in ref. 34) can only be attributed to $\mathrm{Li}^{+}$ion adsorption on either microstructural defects or edges of the SLG for which negative energy values were calculated (e. g. $-0.5 \mathrm{eV}$ for one $\mathrm{Li}^{+}$attached to the graphene edge). Similarly, an enhancement of the $\mathrm{Na}^{+}$adsorption on defective SLG was observed in a first-principles calculations study based on DFT [37]. In this study, for the maximum possible vacancy defect density, cell capacities of $1450 \mathrm{~mA} \mathrm{~h} \mathrm{~g}^{-1}$ were predicted, which are one order of magnitude below the calculated values for SLG/Cu electrodes when the measured surface capacity was referred to the mass of the SLG $\left(\sim 13500 \mathrm{~mA} \mathrm{~h} \mathrm{~g}^{-1}\right)$ by assuming the adsorption of $\mathrm{Na}^{+}$ions on its surface.

\section{Conclusions}

The investigation of the viability of single layer graphene as anode for sodium-ion batteries by means of cyclic voltammetry and galvanostatic cycling revealed that the amount of $\mathrm{Na}^{+}$ions adsorbed/desorbed reversibly per surface area (specific reversible capacity) is very modest regardless of the current density and/or the electrolyte formulation employed, in all cases $<20 \mu \mathrm{A} \mathrm{h} \mathrm{cm}{ }^{-2}$. In any event, these values are comparable, in most cases, to those obtained with bare $\mathrm{Cu}$ electrodes under the same experimental conditions, for which similar potential vs capacity plots were also obtained, thus suggesting that the reversible capacity of the single layer graphene electrode is mostly due to the electrochemical 
response of the copper substrate. These results are in good agreement with recent theoretical calculations showing that the adsorption of $\mathrm{Na}^{+}$ions on the surface of single layer graphene is energetically unfavourable unless that surface includes significant defects density.

\section{Acknowledgments}

$\begin{array}{llll}\text { Financial support from } & \text { IBERDROLA FOUNDATION }\end{array}$ (www.fundacioniberdrola.org, Projects 2014-2015) and the Spanish Ministry of Economy and Competitiveness MINECO (under Projects ENE2011-28318-CO-02 and ENE2014-52189-C2-2-R) is gratefully acknowledged. A. Ramos and N. Cuesta, respectively, thank the Spanish Research Council for Scientific Research (CSIC) for a JAE-Doc contract, co-funded by the European Social Fund (ESF), and the Spanish Ministry of Economy and Competitiveness (MINECO) for a predoctoral grant (BES-2012-052711).

\section{References}

[1] M.D. Slater, D. Kim, E. Lee, C.S. Johnson, Sodium-lon Batteries, Advanced Functional Materials, 23 (2013) 947. 
[2] H. Pan, Y.-S. Hu, L. Chen, Room-temperature stationary sodium-ion batteries for large-scale electric energy storage, Energy \& Environmental Science 6 (2013) 2338.

[3] Y. Kim, K.-H. Ha, S.M. Oh, K.T. Lee, High-Capacity Anode Materials for Sodium-Ion Batteries, Chemistry, A European Journal 20 (2014) 11980.

[4] V. Palomares, M. Casas-Cabanas, E. Castillo-Martínez, M.H. Han, T. Rojo, Update on Na-based battery materials. A growing research path, Energy \& Environmental Science 6 (2013) 2312.

[5] A. Ponrouch, E. Marchante, M. Courty, J.-M.Tarascon, M.R. Palacin, In search of an optimized electrolyte for $\mathrm{Na}$-ion batteries, Energy \& Environmental Science 5 (2012) 8572.

[6] A. Ponrouch, R. Dedryvere, D. Monti, A.E. Demet, J.M. Ateba Mba, L. Croguennec, C. Masquelier, P. Johanssson, M.R. Palacin, Towards high energy density sodium ion batteries through electrolyte optimization, Energy \& Environmental Science 6 (2013) 2361.

[7] D. A. Stevens, J.R. Dahn, The mechanism of lithium and sodium insertion in carbon materials, Journal of the Electrochemical Society 148 (2001) A803.

[8] D.P. DiVincenzo, E.J. Mele, Cohesion and structure graphite intercalation compounds, Physical Review 32 (1985) 2538.

[9] K. Nobuhara, H. Nakayama, M. Nose, S. Nakashini, H. Iba, First-principles study of alkali metal-graphite intercalation, Journal of Power Sources 243 (2013) 585. 
[10] B. Jache, P. Adelhelm, Use of graphite as a highly reversible electrode with superior cycle life for sodium-ion batteries by making use of co-intercalation phenomena, Angewandte Chemie International Edition 53 (2014) 10169.

[11] C. Bommier, W. Luo, W.-Y. Gao, A. Greaney, S. Ma, X. Ji, Predicting capacity of hard carbon anodes in sodium-ion batteries using porosity measurements, Carbon 76 (2014) 165.

[12] K.-L. Hong et al., Biomass derived hard carbon used as a high performance anode material for sodium ion batteries, Journal of Materials Chemistry A 2 (2014) 12733.

[13] J. Zhao et al., Electrochemical and thermal properties of hard carbon-type anodes for Na-ion batteries, Journal of Power Sources 244 (2013) 752.

[14] S. Wenzel, T. Hara, J. Janek, P. Adelhelm, Room-temperature sodium-ion batteries: Improving the rate capability of carbon anode materials by templating strategies, Energy \& Environmental Science 4 (2011) 3342.

[15] R. Alcantara, P. Lavela, G.F. Ortiz, J.L. Tirado, Room-temperature sodiumion batteries: Improving the rate capability of carbon anode materials by templating strategies, Electrochemical Solid-State Letters 8 (2005) A222.

[16] L. Fu, K. Tang, K. Song, P.A. Van Aken, Y. Yu, J. Maier, Nitrogen doped porous carbon fibres as anode materials for sodium ion batteries with excellent rate performance, Nanoscale 6 (2014) 1384.

[17] W. Luo, J. Schardt, C. Bommier, B. Wang, J. Razink, J. Simonsen, X. Ji, Carbon nanofibers derived from cellulose nanofibers as a long-life anode material for rechargeable sodium-ion batteries, Journal of Materials Chemistry A 1 (2013) 10662. 
[18] L. Zeng, W.Li, J. Cheng, J. Wang, X. Liu, Y. Yu, N-doped porous hollow carbon nanofibers fabricated using electrospun polymer templates and their sodium storage properties, RSC Advances 4 (2014) 16920.

[19] T. Chen, Y. Liu, L. Pan, T. Lu, Y. Yao, Z. Sun, D. H. C. Chua, Q. Chen, Electrospun carbon nanofibers as anode materials for sodium ion batteries with excellent cycle performance, Journal of Materials Chemistry A 2 (2014) 4117.

[20] W. Li, L. Zeng, Z. Yang, L. Gu, J. Wang, X. Liu, J. Cheng, Y. Yu, Freestanding and binder-free sodium-ion electrodes with ultralong cycle life and high rate performance based on porous carbon nanofibers, Nanoscale 6 (2014) 693.

[21] V. G. Pol, E. Lee, D. Zhou, F. Dogan, J.M. Calderon-Moreno, C.S. Jonson, Spherical carbon as a new high-rate anode for sodium-ion batteries, Electrochimica Acta 127 (2014) 61.

[22] Y. Cao, L. Xiao, M.L. Sushko, W. Wang, B. Schwenzer, J. Xiao, Z. Nie, L. V. Saraf, Z. Yang, J. Liu, Sodium insertion in hollow carbon nanowires for battery applications, Nanoletters 12 (2012) 3783.

[23] K. Tang, L. Fu, R. J. White, L. Yu, M.M. Titirici, M. Antonietti, J. Maier, Hollow carbon nanospheres with superior rate capability for sodium-based batteries, Advanced Energy Materials 2 (2012) 873.

[24] Y.-X. Wang, S.-L. Chou, H.-K. Liu, S.-X. Dou, Reduced graphene oxide with superior cycling stability and rate capability for sodium storage, Carbon 57 (2013) 202. 
[25] Y. Matsuo, K. Ueda, Pyrolytic carbon from graphite oxide as a negative electrode of sodium-ion battery, Journal of Power Sources 263 (2014) 158.

[26] X. Zhou, X. Zhu, X. Liu, Y. Xu, Y. Liu, Z. Dai, J. Bao, Ultralong Cycle Life Sodium-Ion Battery Anodes Using a Graphene-Templated Carbon Hybrid, The Journal of Physical Chemistry C, 118 (2014) 22426-22431.

[27] X. Zhou, Y.-G. Guo, Highly Disordered Carbon as a Superior Anode Material for Room-Temperature Sodium-Ion Batteries, ChemElectroChem, 1 (2014) 83-86.

[28] Y. Wen, K. He, Y. Zhu, F. Hang, Y. Xu, I. Matsuda, Y. Ishii, J. Cumings, C. Wang, Expanded graphite as superior anode for sodium-ion batteries, Nature Communications 4 (2014) 4033.

[29] G. Radhakrishnan, J.D. Cardema, P.M. Adams, H.I. Kim, B. Foran, Fabrication and Electrochemical Characterization of Single and Multi-Layer Graphene Anodes for Lithium-Ion Batteries, Journal of the Electrochemical Society 159 (2012) A752.

[30] D. Wei, S. Haque, P. Andrew, J. Kivioja, T. Ryhanen, A. Pesquera, A. Centeno, B. Alonso, A. Chuvilin, A. Zurutuza, Ultrathin rechargeable allsolid-state batteries based on monolayer graphene, Journal of Materials Chemistry A 1 (2013) 3177.

[31] N.A. Kaskhedikar, J. Maier, Lithium storage in carbon nanostructures, Advanced Materials 21 (2009) 2664.

[32] I. Cameán, A. Ramos, A.B. Garcia, N. Cuesta, A. Centeno, A. Pesquera, A. Zurutuza, Monocapa de grafeno crecida sobre un film de cobre: aplicación 
como ánodos en baterías de ión-litio de alta potencia. Proceedings XII Reunión del Grupo Español del Carbón, ISBN 978-84-695-8694-5, 2013.

[33] E. Lee, K.A. Persson, Li Absorption and Intercalation in Single Layer Graphene and Few Layer Graphene by First Principles, Nano Letters 12 (2012) 4624.

[34] E. Pollak et al., The Interaction of $\mathrm{Li}^{+}$with Single-Layer and Few-Layer Graphene, Nano Letters 10 (2010) 3386.

[35] M. Zhao et al., Electrochemical stability of copper in lithium-ion battery electrolytes, Journal of the Electrochemical Society 147 (2000) 2874.

[36] C. Ling, F. Mizuno, Boron-doped graphene as a promising anode for $\mathrm{Na}$-ion batteries, Physical Chemistry Chemical Physics 16 (2014) 10419.

[37] D. Datta, J. Li, V.B. Shenoy, Defective graphene as a high capacity anode material for $\mathrm{Na}$ - and $\mathrm{Ca}$-ion batteries, ACS Applied Materials \& Interfaces 6 (2014) 1788. 


\section{TABLES}

\section{Table 1}

Electrochemical parameters from the galvanostatic cycling of SLG/Cu and bare $\mathrm{Cu}$ electrodes at 5 and $50 \mu \mathrm{A} \mathrm{cm}^{-2}$ current densities in different electrolyte solutions

\begin{tabular}{|c|c|c|c|c|c|c|c|c|}
\hline Electrode & $\begin{array}{l}\text { Current } \\
\text { density } \\
\left(\mu \mathrm{Acm}^{-2}\right)\end{array}$ & $\begin{array}{c}\mathrm{C}_{\text {disc }} \\
1 \mathrm{st} \mathrm{cycle} \\
\left(\mu \mathrm{A} \mathrm{h} \mathrm{cm} \mathrm{cm}^{-2}\right)\end{array}$ & $\begin{array}{c}\mathrm{C}_{\text {disc }} \\
\text { 2nd cycle } \\
\left(\mu \mathrm{A} \mathrm{h} \mathrm{cm} \mathrm{cm}^{-2}\right)\end{array}$ & 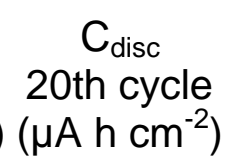 & $\begin{array}{c}\mathrm{C}_{\text {disc }} \\
\text { last cycle } 1 \\
\left(\mu \mathrm{A} \mathrm{h} \mathrm{cm} \mathrm{cm}^{-2}\right)\end{array}$ & $\begin{array}{c}\mathrm{C}_{\text {irr }}^{4} \\
1 \text { st cycle } \\
(\%)\end{array}$ & $\mathrm{R}^{5}$ & $\mathrm{R}^{6}$ \\
\hline $\mathrm{SLG} / \mathrm{Cu}^{1}$ & 5 & 177.2 & 21.0 & 15.9 & $14.3^{\mathrm{a}}$ & 92 & 76 & 68 \\
\hline $\mathrm{SLG} / \mathrm{Cu}^{1}$ & 50 & 49.7 & 4.6 & 1.6 & $1.0^{\mathrm{b}}$ & 92 & 36 & 22 \\
\hline $\mathrm{SLG} / \mathrm{Cu}^{2}$ & 5 & 100.1 & 6.7 & 4.6 & $5.9^{c}$ & 95 & 68 & 88 \\
\hline $\mathrm{SLG} / \mathrm{Cu}^{2}$ & 50 & 55.0 & 5.2 & 2.3 & $1.1^{\mathrm{b}}$ & 93 & 45 & 23 \\
\hline $\mathrm{SLG} / \mathrm{Cu}^{3}$ & 5 & 73.5 & 21.3 & 18.4 & $14.6^{c}$ & 89 & 87 & 68 \\
\hline $\mathrm{SLG} / \mathrm{Cu}^{3}$ & 50 & 14.8 & 4.7 & 1.7 & $1.1^{\mathrm{a}}$ & 78 & 35 & 26 \\
\hline $\mathrm{Cu}^{1}$ & 5 & 81.5 & 4.6 & 2.1 & $2.3^{\mathrm{a}}$ & 98 & 45 & 49 \\
\hline $\mathrm{Cu}^{1}$ & 50 & 40.9 & 4.6 & 1.8 & $0.5^{\mathrm{b}}$ & 91 & 40 & 11 \\
\hline $\begin{aligned} & 1 \mathrm{M} \mathrm{NaPF} \\
&= {\left[\left(\mathrm{C}_{\text {disc, } 1 \mathrm{~s}}\right.\right.} \\
& {\left[\left(\mathrm{C}_{\text {disc, } 20 \text { th }}\right.\right.} \\
&-\mathrm{C}_{\text {disc, } 2 \mathrm{dd}}\end{aligned}$ & cycle $) / C_{\text {disc, }}$ ? & $\begin{array}{l}\text { (C). }{ }^{2} 1 \mathrm{M} \mathrm{N} \\
\text { harge, } 1 \text { st cycle)/ } \\
\text {, 2nd cycle } / \mathrm{C}_{\text {dis }} \\
\text { 2nd cycle] x } 10\end{array}$ & $\begin{array}{l}\mathrm{aPF}_{6}(\mathrm{EC}: \mathrm{PC} \\
/ \mathrm{C}_{\text {disc, }} \text { 1st cycle] } \\
\text { sc, 2nd cycle] x } \\
\text { 0. }^{\mathrm{a}} 100^{\text {th }} \mathrm{cyc}\end{array}$ & $\begin{array}{l}\text { C) } .{ }^{3} 1 \mathrm{M} \mathrm{Na} \\
\times 100 .{ }^{5} \mathrm{Ca} \\
100 .{ }^{6} \text { Total } \\
\text { cle. }{ }^{b} 500 \text { th }\end{array}$ & $\begin{array}{l}\mathrm{aClO}_{4}(\mathrm{PC}) .{ }^{4} \\
\text { apacity retent } \\
\text { capacity rete } \\
\text { cycle. }{ }^{\mathrm{C}} 50^{\text {th }} \mathrm{C}\end{array}$ & $\begin{array}{l}{ }^{4} \text { Irrever } \\
\text { tion cyc } \\
\text { ention = } \\
\text { cycle }\end{array}$ & & $\begin{array}{l}\text { acity } \\
20= \\
\text { st cycle }\end{array}$ \\
\hline
\end{tabular}




\section{CAPTIONS FOR FIGURES}

Figure 1. Voltammograms of cycles 1,2 and 5 of SLG/Cu and bare Cu electrodes using $1 \mathrm{M} \mathrm{NaPF}_{6}$ (EC:DEC, 1:1, w:w) as electrolyte solution.

Figure 2. Profiles of first, second, tenth and fiftieth discharge-charge cycles for $\mathrm{SLG} / \mathrm{Cu}$ and bare $\mathrm{Cu}$ electrodes at a current density of $50 \mu \mathrm{A} \mathrm{cm}^{-2}$ and $1 \mathrm{M} \mathrm{NaPF}_{6}$ (EC:DEC, 1:1, w:w) as electrolyte solution.

Figure 3. Galvanostatic cycling at a current density of $50 \mu \mathrm{A} \mathrm{cm}{ }^{-2}$ for $\mathrm{SLG} / \mathrm{Cu}$ electrode with different electrolyte solutions. 


\section{FIGURE 1}
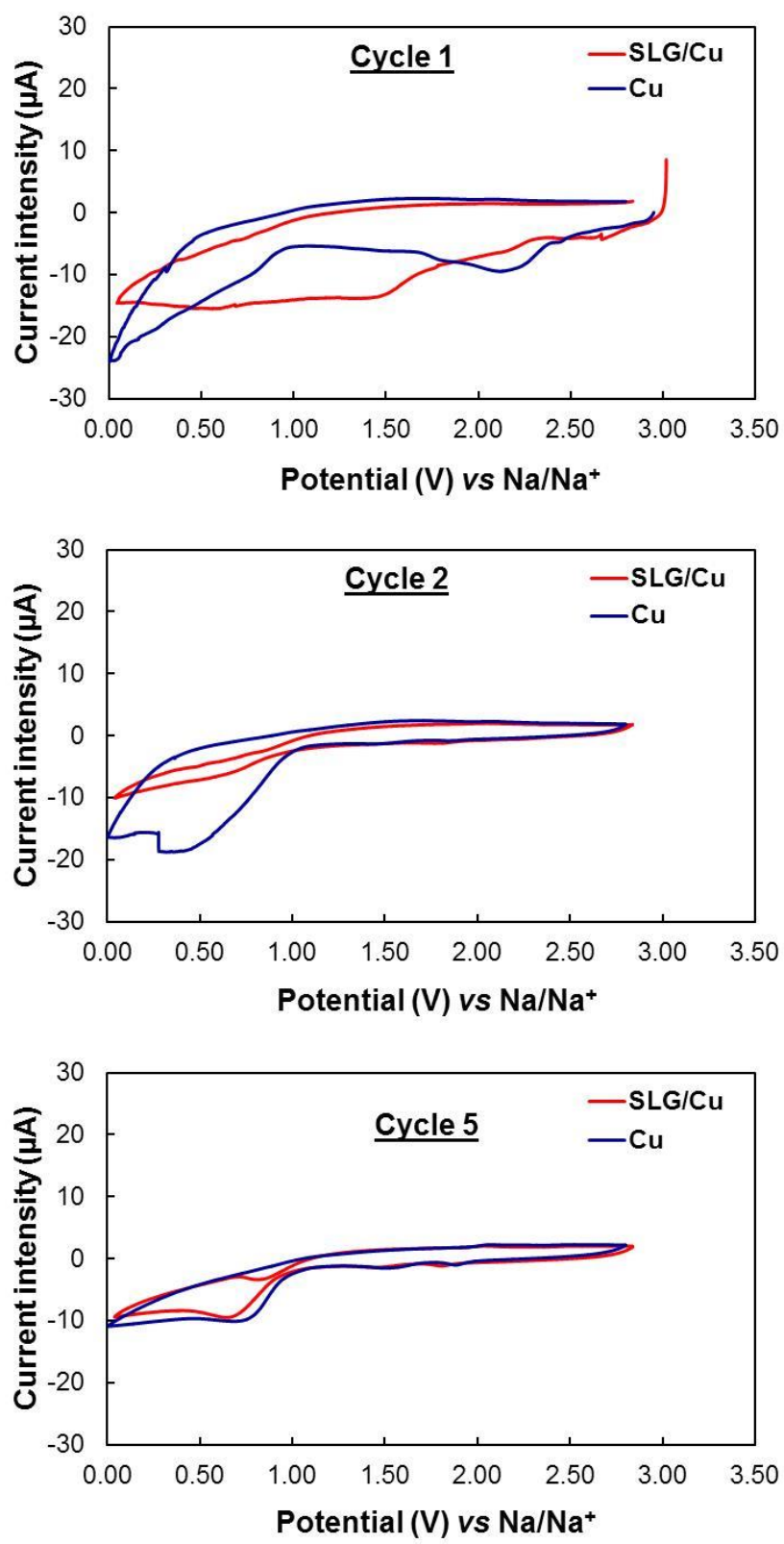

Fig. 1. Voltammograms of cycles 1,2 and 5 of $\mathrm{SLG} / \mathrm{Cu}$ and bare $\mathrm{Cu}$ electrodes using $1 \mathrm{M} \mathrm{NaPF}_{6}$ (EC:DEC, 1:1, w:w) as electrolyte solution 


\section{FIGURE 2}
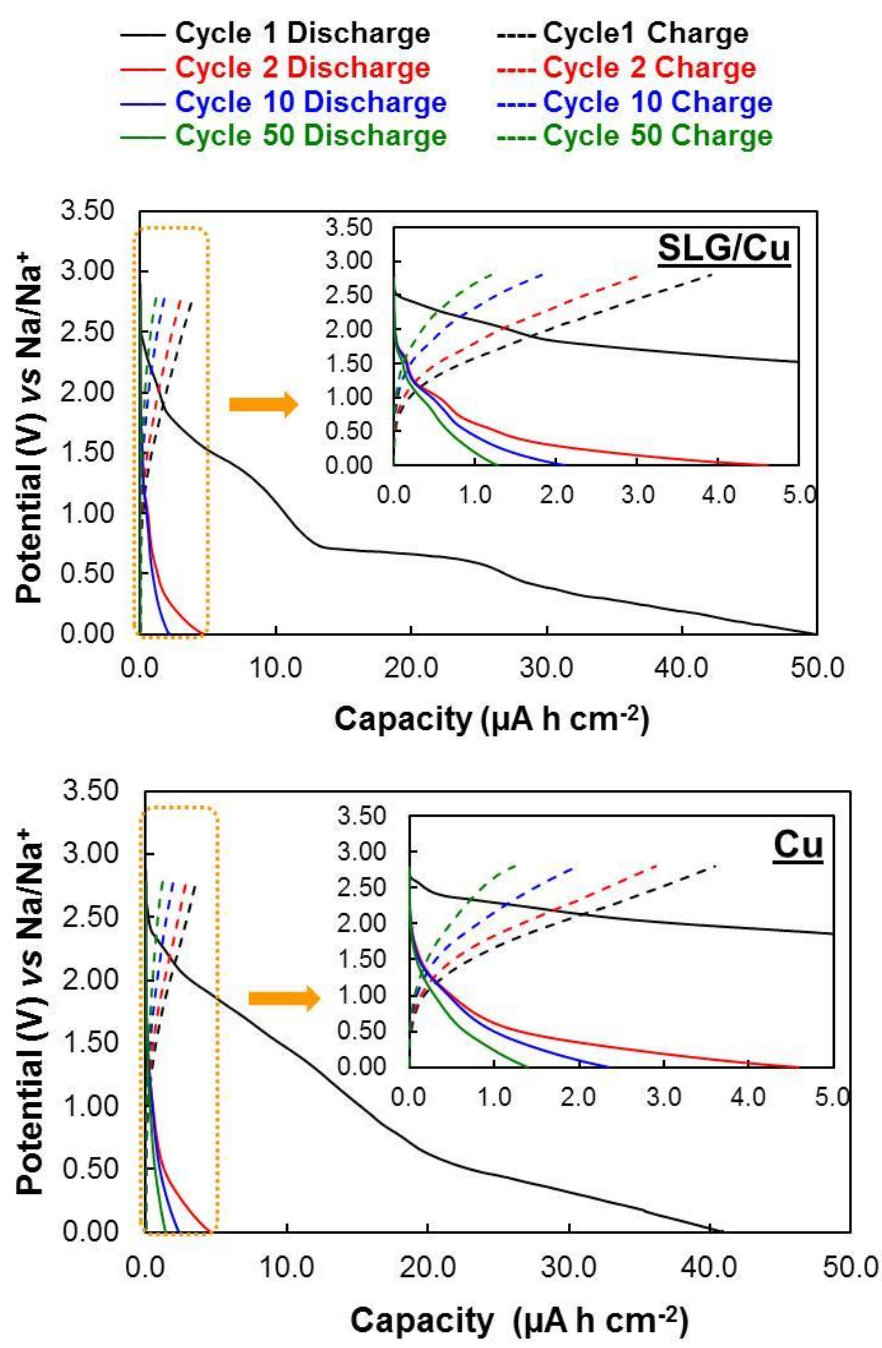

Fig. 2. Profiles of first, second, tenth and fiftieth discharge-charge cycles for SLG/Cu and bare Cu electrodes at a current density of $50 \mu \mathrm{A} \mathrm{cm}^{-2}$ and $1 \mathrm{M} \mathrm{NaPF}_{6}$ (EC:DEC, 1:1, w:w) as electrolyte solution. 


\section{FIGURE 3}
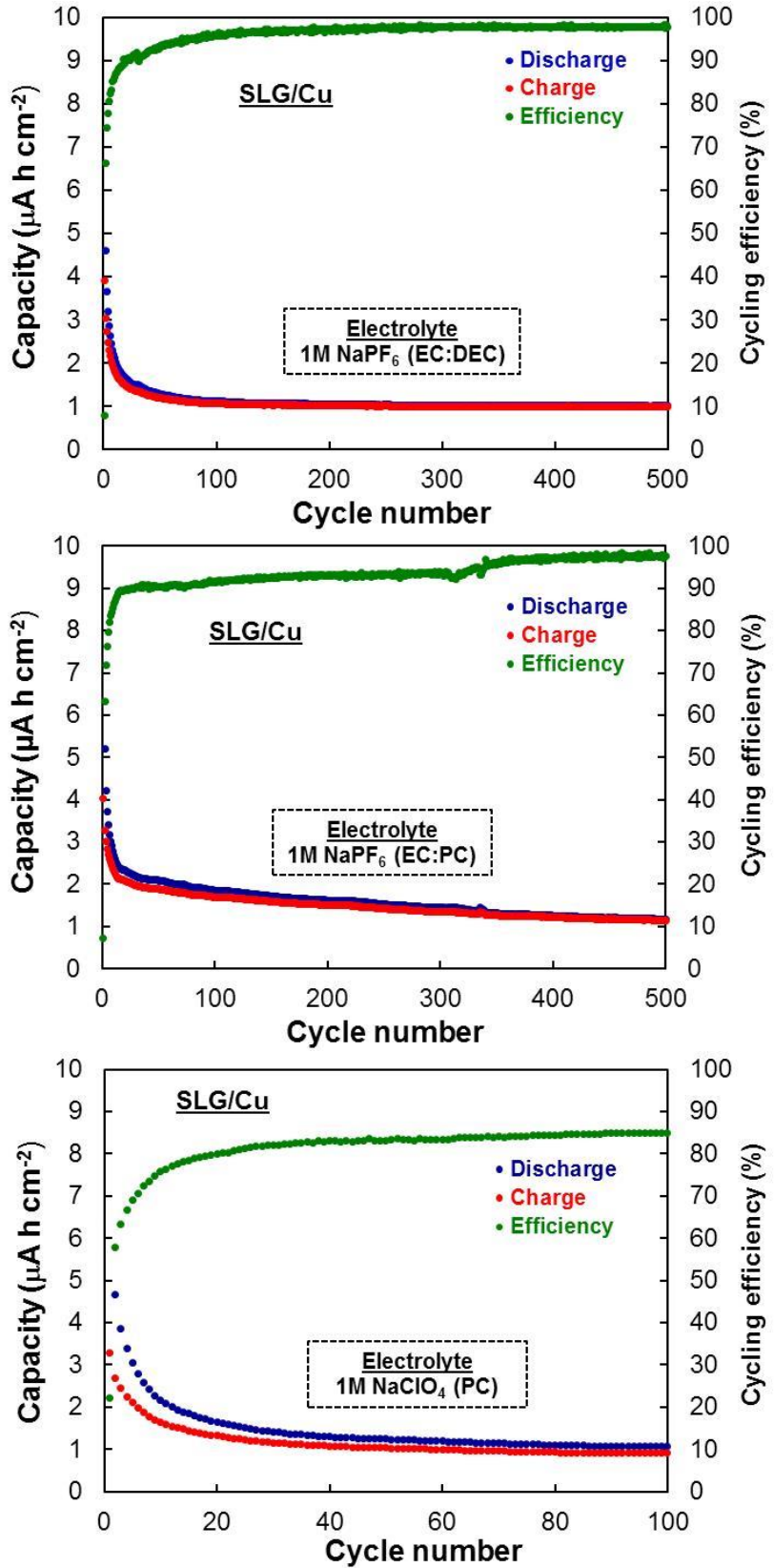

Fig. 3. Galvanostatic cycling at a current density of $50 \mu \mathrm{A} \mathrm{cm}{ }^{-2}$ for SLG/Cu electrode with different electrolyte solutions. 


\section{ELECTRONIC SUPPORTING INFORMATION}

Figure S1. Raman spectrum (a) and SEM and TEM images (b and c) of SLG as provided by the supplier

Figure S2. Normalized voltage versus capacity profiles for the SLG/Cu electrode cycled in $\mathrm{NaPF}_{6}$ (EC:DEC) electrolyte at current densities of 50 and $5 \mu \mathrm{A} \mathrm{cm}{ }^{-2}$

Figure S3. Galvanostatic cycling at a current density of $5 \mu \mathrm{A} \mathrm{cm}{ }^{-2}$ for $\mathrm{SLG} / \mathrm{Cu}$ electrode with different electrolyte solutions

Figure S4. Galvanostatic cycling at current densities of 50 and $5 \mu \mathrm{A} \mathrm{cm}$ for bare Cu electrode of reference 


\section{FIGURE S1}
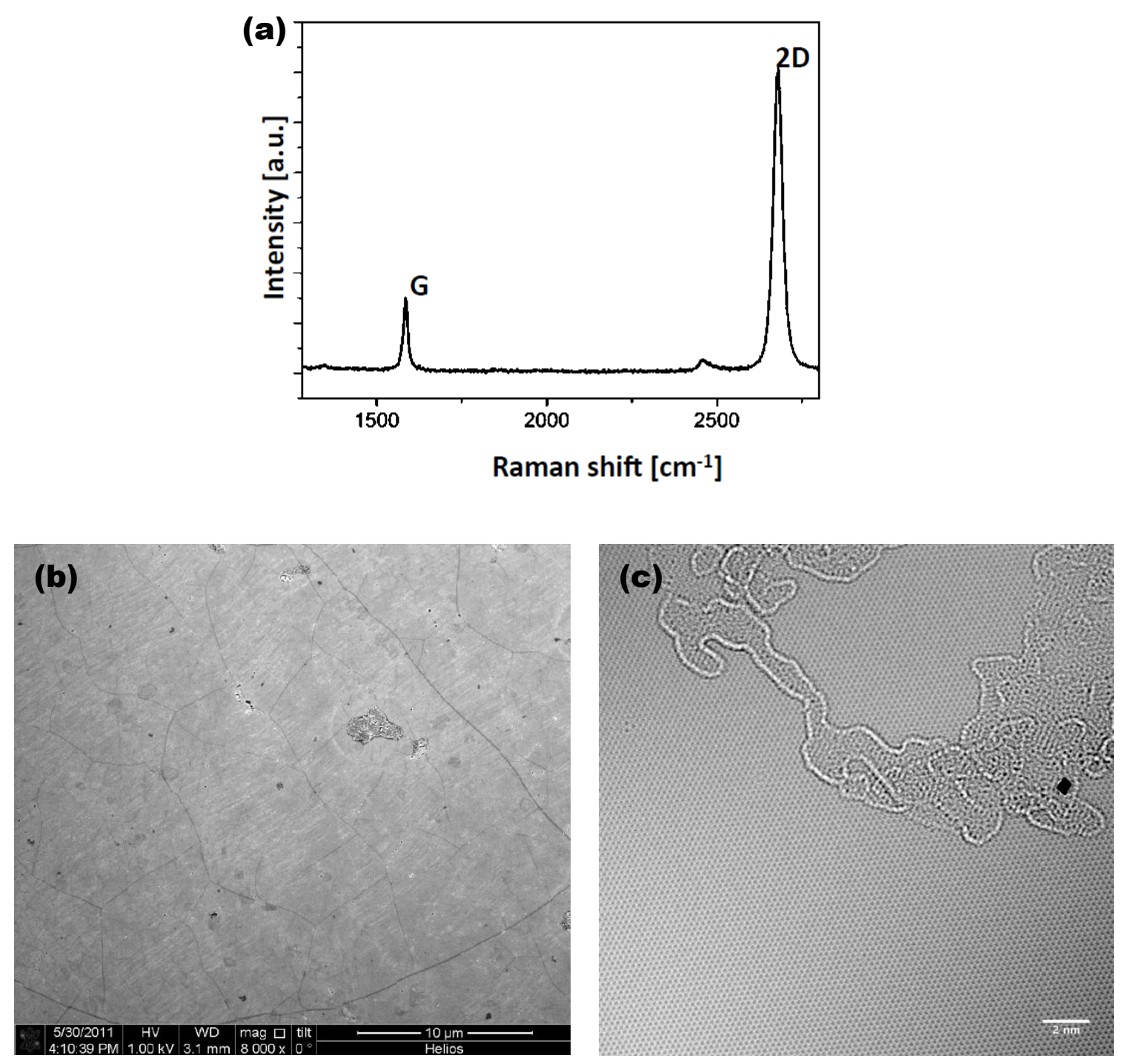

Figure S1. Raman spectrum (a) and SEM and TEM images (b and c) of SLG as provided by the supplier 


\section{FIGURE S2}
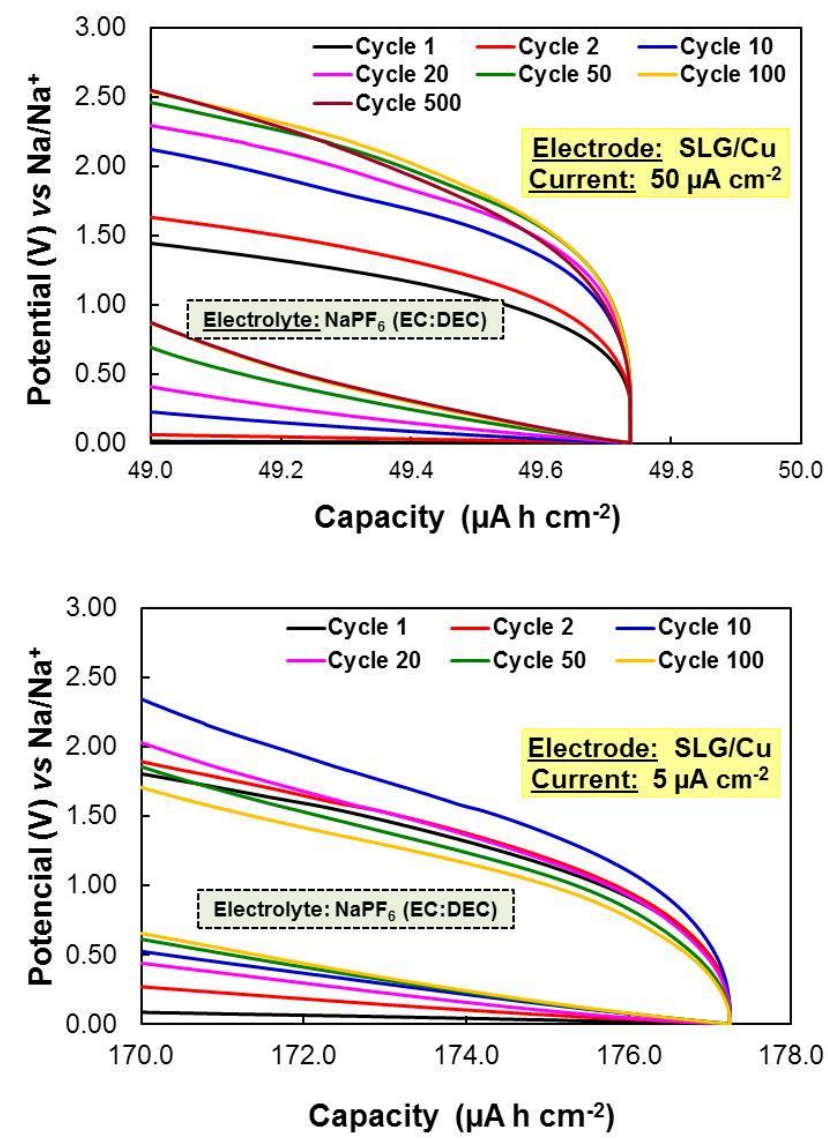

Fig. S2. Normalized voltage versus capacity profiles for the SLG/Cu electrode cycled in $\mathrm{NaPF}_{6}$ (EC:DEC) electrolyte at current densities of 50 and $5 \mu \mathrm{Acm}^{-2}$ 
FIGURE S3
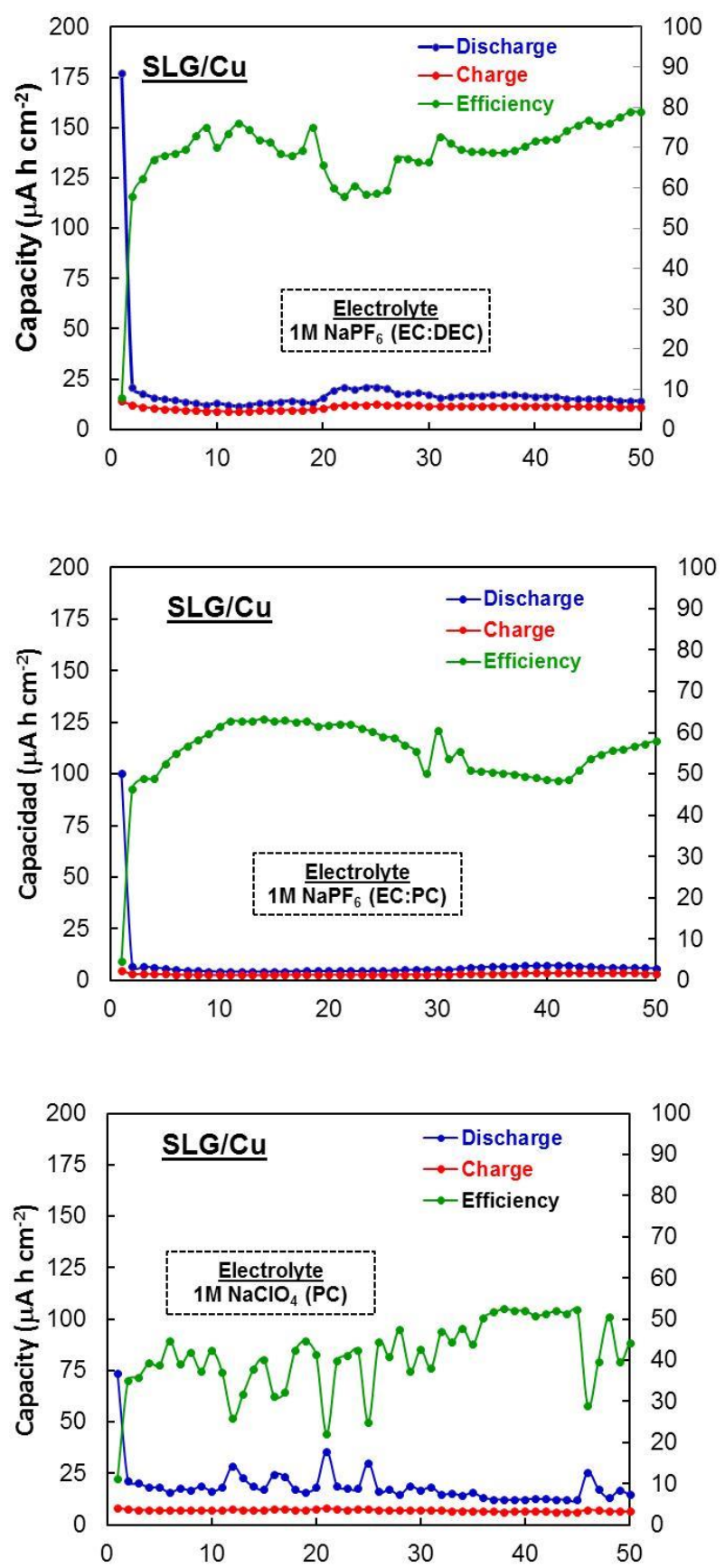

Fig. S3. Galvanostatic cycling at a current density of $5 \mu \mathrm{A} \mathrm{cm}{ }^{-2}$ for SLG/Cu electrode with different electrolyte solutions 


\section{FIGURE S4}
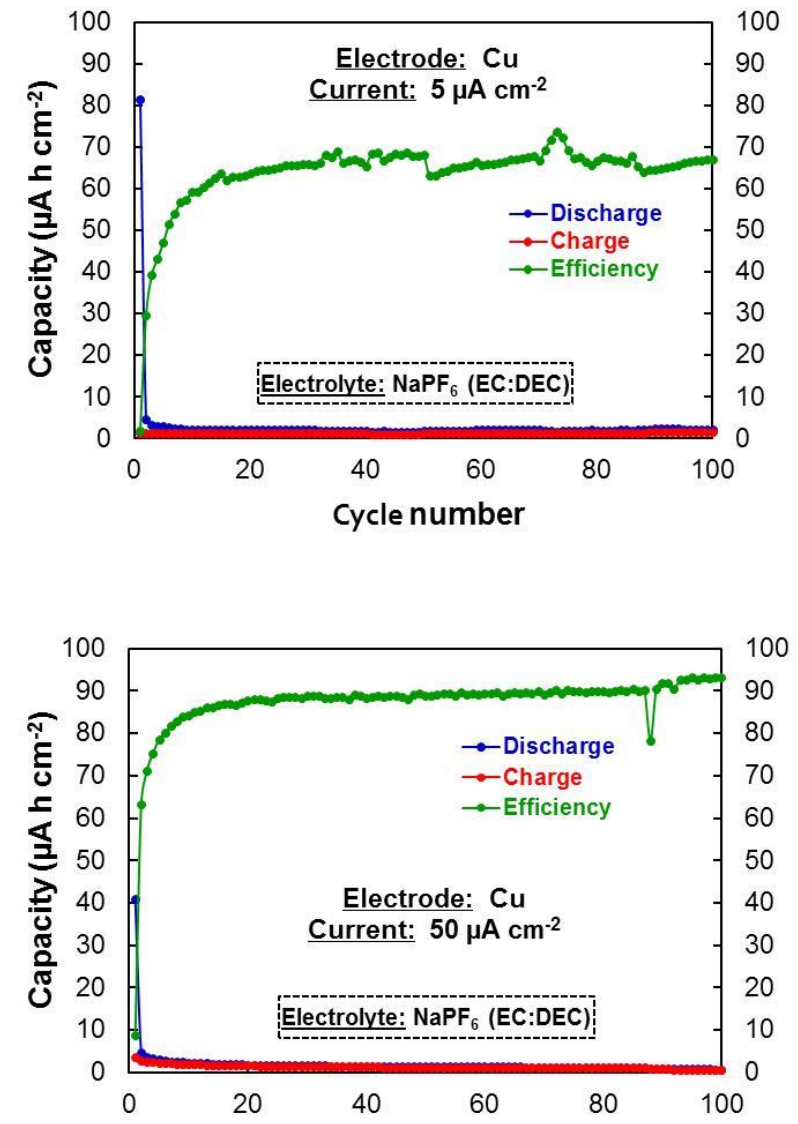

Fig. S4. Galvanostatic cycling at current densities of 50 and $5 \mu \mathrm{A} \mathrm{cm}{ }^{-2}$ for bare $\mathrm{Cu}$ electrode of reference 